\title{
Calculation of Agricultural Drain Spacing Taking into Account Regularity of Water Exchange in the Vadose Zone
}

\author{
I. Nikolskii-Gavrilov ${ }^{1}$, V. V. Pchyolkin ${ }^{2}$, C. Landeros-Sánchez ${ }^{3} \&$ Montero-Aguirre Saul $^{1}$ \\ ${ }^{1}$ Colegio de Postgraduados Campus Montecillo, Texcoco, México \\ ${ }^{2}$ Russian State Agrarian University, Moscow, Russia \\ ${ }^{3}$ Colegio de Posgraduados Campus Veracruz, Veracruz, México \\ Correspondence: C. Landeros-Sánchez, Colegio de Posgraduados Campus Veracruz, Km 88.5 Carretera Federal \\ Xalapa-Veracruz, vía Paso de Ovejas entre Puente Jula y Paso San Juan, Tepetates, C.P. 91690, Apartado Postal \\ 421, Veracruz, México. E-mail: clandero@colpos.mx
}

Received: December 1, 2016

Accepted: February 4, 2017 Online Published: March 15, 2017

doi:10.5539/jas.v9n4p109

URL: https://doi.org/10.5539/jas.v9n4p109

\begin{abstract}
Conventional analytical formulae for calculation of subsurface drain spacing for maintaining a desired water table depth in agricultural areas, such as Hooghoudt's formula, are based on using the ratio between the soil saturated hydraulic conductivity $K_{s}$ and the groundwater recharge rate $q$. It is well known that selection of the $q$ value as one of the principle drainage criterion is one of the problems of the drain spacing calculation. In this paper, it is illustrated that for steady state conditions and, in case of homogeneous soil profile, the ratio $q / K_{\mathrm{s}}$ can be substituted by an analytical function that takes into account the regularity of infiltration through the vadose zone. This function can be derived from the soil moisture content in the root zone and other well-known hydrodynamic soil parameters. An example of drain spacing calculation is presented.
\end{abstract}

Keywords: agricultural drainage, design, soil water regime

\section{Introduction}

In practice, subsurface drainage design for maintaining the depth of the water table at a particular depth is performed by using equations based on steady state water flow in saturated and unsaturated zones of soil profile. For calculation of the horizontal drain spacing, it is necessary to know the value of the groundwater recharge rate $q$ and the soil's saturated hydraulic conductivity $K_{s}$. Additionally, information about climatic and hydrogeological conditions as well as the type of land use (rain-fed or irrigation, and subsurface drainage together with surface drainage or without it among others) are necessary to complete the calculation. The $q$ value is one of the main drainage criteria and it frequently ranges between 1 to $10 \mathrm{~mm} /$ day. To date, there are no well-defined criteria concerning the $q$ values; however, it depends on various factors that should be taken into consideration, i.e., waterlogging, climatic, soil and hydrogeological conditions and the type of land use. As regards the former, Ritzema (1994) proposed some criteria for the selection or assessment of $q$ values. The general form of the equation used to calculate the drain spacing $L(\mathrm{~m})$ in homogeneous soils can be expressed for steady state conditions by (Ritzema, 1994; Skaggs and van Schilfgaarde, 1999; Mishra and Singh, 2007; Hay, 2010; Averyanov, 2015):

$$
L=f_{1}\left[\left(K_{\mathrm{s}} / q\right) \times f_{2}\left(h, r_{d r}, \Phi\right)\right]
$$

Where, $f_{1}$ and $f_{2}$ correspond to analytical functions; $K_{S}$ is the saturated hydraulic conductivity ( $\mathrm{m} /$ day); $q$ is the groundwater recharge rate or drain discharge rate (note that $K_{s}$ and $q$ have the same dimension - $\mathrm{m} /$ day); $h$ is a water table height in the middle of drain-spacing above the water level in drains (m): $h=d_{d r}-d_{w t} ; d_{d r}$ is drain depth $(\mathrm{m}), d_{w t}$ is the depth to the water table $(\mathrm{m}), r_{d r}$ and $\Phi$ are the drain radius and "hydraulic resistance", respectively (m). A specific case of the relationship (1) is Hooghoudt's formula (Ritzema, 1994):

$$
L=2 h \sqrt{\frac{K_{S}}{q}\left(1+\frac{2 D_{e}}{h}\right)}
$$


Where, $L$ corresponds to the drain spacing $(\mathrm{m}) ; D_{e}$ is an "equivalent depth" (m) determined from Hooghoudt's graphs, and $D_{e}$ represents the "hydraulic resistance", which takes into account the drain radius and the relationship between the depth to the impermeable layer and the drain spacing.

Analytical equations for calculating the drain spacing on agricultural areas do not take into account the soil moisture content in the root zone and the unsaturated hydraulic properties of soils. Moreover, it is commonly assumed that the groundwater recharge rate between drains is uniformly distributed (Ritzema, 1994; Skaggs \& van Schilfgaarde, 1999; Christen et al., 2001; Kladivko et al., 2004; Mileham et al., 2008; Fuentes et al, 2009). For steady state conditions, the groundwater recharge rate is equal to the infiltration rate through the vadose zone. Currently, there are well-developed methods for the vadose zone; however, there is a practical need to derive a simple approach for calculating the drainage spacing by means of analytical formulae. These calculations should incorporate the unsaturated hydraulic conductivity and soil water retention functions of the vadose zone. Furthermore, calculations should also consider the soil moisture content in the root zone (Nikolskii, 1998). One way to include the hydrodynamic properties of vadose zone in the determination of drain spacing is by means of computer programs, which can calculate the water movement in the unsaturated and saturated zones of the soil profile.

The purpose of this paper is to develop an analytical formula for calculating the drain spacing by making use of soil moisture content in the root zone, the water table depth, and other well-known hydrodynamic soil parameters.

\section{Method}

The main assumptions used in developing the method proposed herein are:

$>$ The soil profile is homogenous;

$>$ The moisture content $\theta_{r}$ is maintained in a root zone of thickness $z_{r}$, at $z=z_{r} / 2$ during a certain period, i.e., a week, month, growing season or year; and

$>$ The groundwater recharge rate $q(\mathrm{~m} /$ day $)$ in steady state conditions is equal to the vertical flow rate through the vadose zone determined from Darcy's law for unsaturated soils. This relationship can be expressed as:

$$
q=K_{d}\left(\mathrm{~d} P_{\theta} \mathrm{d} z-1\right)
$$

Where, $K_{\theta}$ is the unsaturated hydraulic conductivity ( $\mathrm{m} /$ day) as a function of the volumetric moisture content $\theta$ $\left(\mathrm{m}^{3} / \mathrm{m}^{3}\right) ; P_{\theta}$ is the matrix potential of soil water $(\mathrm{m})$ as a function of the moisture content $\theta$, and $z$ corresponds to the depth from the soil surface $(\mathrm{m})$.

The unsaturated hydraulic conductivity as a function of the volumetric moisture content $K_{\theta}(\theta)$ and the matrix potential of soil water as a function of the moisture content $P_{(}(\theta)$ are given by (Averyanov, $1949 \& 2015$; Brooks \& Corey, 1964; van Genuchten, 1980; Mualem, 1978):

$$
K_{\theta}=K_{s} f_{3}(\theta)
$$

and,

$$
P_{\theta}=P_{0} f_{4}(\theta)
$$

Where, $K_{s}$ is the saturated hydraulic conductivity (m/day); $P_{0}$ is a constant of the relationship $P_{\theta}(\theta)(\mathrm{m})$, and $f_{3}(\theta)$ and $f_{4}(\theta)$ are functional relationships for Equations (4) and (5).

To determine the ratio $K_{s} / q$, one can integrate Equation (3) by using the following boundary conditions:

$z=z_{r} / 2\left(z_{r}\right.$ is the root zone depth), the moisture content is $\theta=\theta_{r}$. At this condition the saturation $S$ is defined by the following boundary condition expression:

$$
S=S_{r}=\left(\theta_{r}-\theta_{0}\right) /\left(\theta_{S}-\theta_{0}\right)
$$

Where, $\theta_{s}$ is the saturation soil moisture content, and $\theta_{0}$ is the residual moisture content. At the water table $z=$ $d_{w t}$, the moisture content is given by:

$$
\theta=\theta_{S} \text { and the saturation } S=1
$$

Using the boundary condition given by Equation (6) and by integrating Equation (3), one can obtain:

$$
\left(d_{w t}-\frac{z_{r}}{2}\right)=\int_{S_{r}}^{1} \frac{P_{\theta}{ }^{\prime}(S) d S}{1-\frac{q}{K_{\theta}}}
$$


Where, $K_{\theta}=K_{\theta}(S)$. The solution of Equation (8) expressed as a ratio of $K_{\theta} / q$ or $K_{s} / q$ depends on the functions $P_{\theta}$ $(S)$ and $K_{\theta}(S)$. This means that a drain spacing $L$ can be calculated by means of Equation (1) or by using Equation (2) without the ratio $K_{s} / q$. This can be achieved with the aid of well-known parameters, such as climatic conditions, the hydrodynamic soil properties $P_{\theta}(S)$ and $K_{\theta}(S)$, the soil moisture content in the root zone $\theta_{r}$ (or $S_{r}$ ) and the depth to the water table $d_{w t}$ without having selected the groundwater recharge rate $q$ in advance.

\section{Results and Discussion}

As an example, we consider the water retention function given by Richards (Ritzema, 1994):

$$
P_{\theta}=P_{0} \ln S
$$

Where, $P_{0}>0$ and it corresponds to the air entry pressure depending on soil texture; $S=\left(\theta-\theta_{0}\right) /\left(\theta_{s}-\theta_{0}\right)$, and the unsaturated hydraulic conductivity function given by (Averyanov, $1949 \&$ 2015; Brooks \& Corey, 1964):

$$
K_{\theta}=K_{S} S^{n}
$$

Where, $n$ is an exponent ranging from 3.5 to 24.5 depending on the soil texture and structure (Mualem, 1978).

Combining Equations (8) and (9) and (10), it gives as a result:

$$
\frac{q}{K_{s}}=\frac{S_{r}^{n}-\exp (-\delta)}{1-\exp (-\delta)} \quad \text { or } \quad \frac{K_{s}}{q}=\frac{1-\exp (-\delta)}{S_{r}^{n}-\exp (-\delta)}
$$

Where, $\delta$ corresponds to the dimensionless depth to the water table calculated from half the depth to the water table and it can be expressed as:

$$
\delta=n\left(d_{w t}-z_{r} / 2\right) / P_{0}
$$

According to Equation (11), the condition where the groundwater recharge is greater than zero $(q>0)$ takes place when $S_{r}^{n}>\exp (-\delta)$. In general, the $q$ value increases as $\theta$ and $d_{w t}$ increase. For a shallow water table, i.e., when $S_{r}^{n}<\exp (-\delta)$, the upward water flow $(q<0)$ takes place. For a deep groundwater table (approximately when $\left.d_{w t} \geq 2 \mathrm{~m}\right)$, i.e. when $S_{r}^{n}>>\exp (-\delta)$, the groundwater recharge $q$ can be expressed as a function of the root zone saturation given by:

$$
q=K_{s} S_{r}^{n}
$$

Obviously, Equation (11) is valid only for shallow groundwater, i.e., when $d_{w t}$ is small and strongly influences the soil moisture content in the root zone, and $\theta_{r}$ or $S_{r}$ cannot be considered as an independent variable. For a given shallow water table, if calculated values of upward flow $q$ exceed the potential evapotranspiration $E T_{0}$, it is necessary to take $q=E T_{0}$. Similar to Equation (8), this approach has been used to calculate the maximum value of steady upward flow from the water table to the root zone by Anat et al. (1965) and Wesseling (1991).

In order to verify if Equation (11) describes objectively the regularity of water exchange in the vadose zone, experimental data published by Pchyolkin (2003) were used. These data were obtained in Russia in two experimental stations: one with peat soil and another with alluvial loamy soil. Each experimental station included 8 cylindrical lysimeters with non-altered soil columns of $2 \mathrm{~m}$ depth and a surface of $2 \mathrm{~m}^{2}$, in which different water table depths were studied. The water balance in the vadose zone for periods of 3 to 5 days is obtained by the expression:

$$
W_{f}=W_{i n}+P r+I r-E T \pm q \text { or } W_{f}-W_{\text {in }}=P r+I r-E T \pm q
$$

Where, $W_{f}$ and $W_{i n}$ are the water storage in the soil profile above the water table at the end and the beginning of each period, respectively (mm); $P r$ is the precipitation $(\mathrm{mm}), I r$ is the irrigation $(\mathrm{mm}), E T$ corresponds to the evapotranspiration $(\mathrm{mm} /$ day), and $q$ corresponds to the water exchange value between the vadose zone and ground water ( $\mathrm{mm} /$ day) $(+q$ and $-q$ correspond to upward and downward flow, respectively). The lysimeters with peat soil and with alluvial loamy soil had spring wheat and beat roots respectively and both under sprinkle irrigation. The water table in all experiments was maintained at depths ranging from 0.5 to $2 \mathrm{~m}$. The following considerations were taken for the experiments with spring wheat, when $d_{w t} \geq 1 \mathrm{~m}, z_{r}=0.5 \mathrm{~m}$, and for $d_{w t}=0.5 \mathrm{~m}$, $z_{r}=0.3 \mathrm{~m}$. In the case of the experiments with beat roots, when $d_{w t} \geq 1 \mathrm{~m}, z_{r}=0.4 \mathrm{~m}$, and for $d_{w t}=0.5 \mathrm{~m}, z_{r}=0.2$ $\mathrm{m}$.

The hydrodynamic properties of these soils were the following:

Peat soil: $\theta_{s}=0.85, \theta_{0}=0.45, K_{s}=0.26 \mathrm{~m} / \mathrm{d}, P_{0}=1.08 \mathrm{~m}$; alluvial loamy soil: $\theta_{s}=0.52, \theta_{0}=0.25$ (all in volumetric units), $K_{s}=0.25 \mathrm{~m} / \mathrm{d}, P_{0}=1.08 \mathrm{~m}$.

The soil moisture content values in the root zone of the studied soils were: 
Peat soil: $0.55<\theta_{r} \leq 0.80$ or $0.25<S_{r} \leq 0.87$.

Alluvial loamy soil: $0.35<\theta_{r} \leq 0.45$ or $0.37<S_{r} \leq 0.74$.

Figure 1 shows the results calculated from Equation (11) and the measured values of $q / K_{s}$ ratio for samples of peat soil and alluvial loamy soil. The normalized mean square error of calculated and measured data of $q / K_{s}$ is less than $10 \%$ when using $n=6.4$ for peat soil samples and $n=7$ for alluvial loamy soil samples. Thus, the results suggest that experimental data can be accurately described by Equation (11) when $n$ values correspond to 6.4 and 7 for peat and alluvial loamy soil samples, respectively.

In the case of homogeneous soil profile, the ratio $K_{s} / q$ from Equation (11) could be used for calculating drain spacing $L$ from Equation (1) or in particular with Hooghoudt's formula (Equation (2)). Substituting Equation (11) in Equation (2), the modified Hooghoudt's formula can be expressed as:

$$
L=2 h \sqrt{\left(\frac{1-\exp (-\delta)}{S_{r}^{n}-\exp (-\delta)}\right)\left(1+\frac{2 D_{e}}{h}\right)}
$$
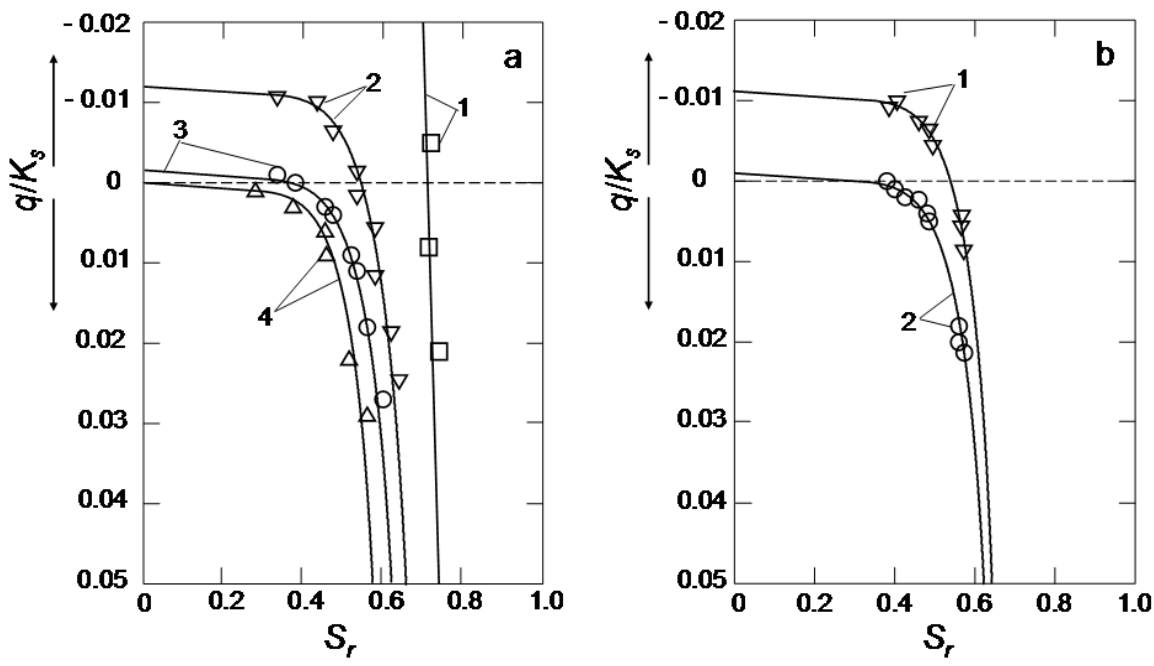

Figure 1. Comparison between $q$ values calculated with Equation (11) (solid lines) and those measured in lysimeters (points) with non-altered columns of a peat soil for spring wheat (a) and an alluvial loamy soil for beat roots (b) with sprinkle irrigation. In Figure 1a, plot 1 corresponds to dimensionless water table depth $\delta=$ 2.07 (or dimension depth $d_{w t}=0.5 \mathrm{~m}$ ); plot 2, $\delta=4.44(1.0 \mathrm{~m})$; plot 3, $\delta=7.41(1.5 \mathrm{~m})$; plot 4, $\delta=10.37(2.0 \mathrm{~m})$; in Figure 1b, plot 1, $\delta=4.48(1.0 \mathrm{~m})$; plot 2, $\delta=7.28(1.5 \mathrm{~m})$

Equation (15) shows that drain spacing $L$ depends not only on the ratio $K_{s} / q$ but on the soil water saturation $S_{r}$ (or soil moisture content $\theta_{r}$ ) and the dimensionless water table depth $\delta$ (or dimensional depth $d_{w t}$ ), as well as on hydrodynamic soil characteristics $\theta_{S}$ and $\theta_{0}$, and parameters $P_{0}$ and $n$. Equation (15) can be used in practice to calculate drain spacing $L$ and reveals that $L$ value is very sensitive to the soil moisture content in the root zone. To calculate drain spacing for a certain plot it is not necessary to select unknown recharge rate $q$ from bibliography, but it is necessary to know values of $\theta_{S}, \theta_{0}, P_{0}$ and $n$ for Equation (15). These data, which depend on soil texture, can be obtained from experiments or from publications like the one reported by Fuentes Ruiz, Havercamp and Parlange (1991). It is also possible to make previous calibration of drain spacing calculations for selected plot with Equation (15) comparing these data with local or regional $L$ values from field drainage.

Some scenarios as well as a practical example concerning the proposed approach for drain spacing calculation are given below. Figure 2 depicts one of the scenarios used herein to calculate the drain spacing $L$ for homogeneous soil profile and steady state condition. 


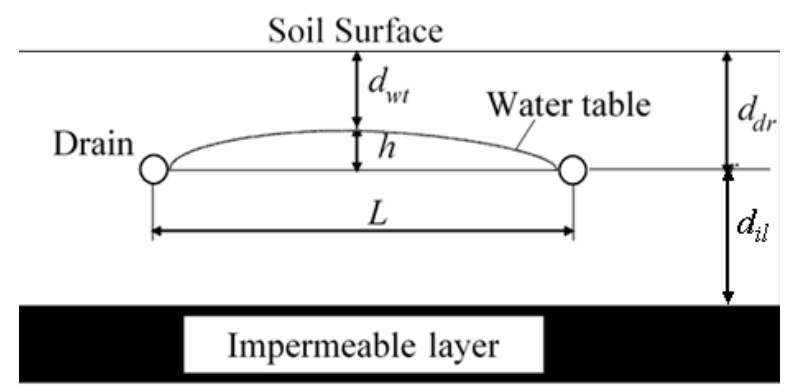

Figure 2. A schematic representation to calculate drain spacing $L$ for homogeneous soil profile and steady state condition

\subsection{Scenarios Concerning Drain Spacing}

3.1.1 Case 1. Agricultural Irrigated Non-Saline Land with Homogeneous Soil Profile, sprinkle irrigation and Pipe Distribution of Water

In this case for steady state condition, deep percolation of irrigation water through soil profile is equal to groundwater recharge rate $q$ and the expression $\frac{1-\exp (-\delta)}{S_{r}^{n}-\exp (-\delta)}$ in Equation (15) can be calculated depending on the soil moisture content in a root zone $\theta_{r}$ (or saturation $S_{r}$ ) and the water table depth $d_{w t}$ (or its dimensionless value $\delta)$.

\subsubsection{Case 2. Rainfed Land in Humid Zone}

The scenario here is more complicated due to the following considerations:

$>\quad$ On one side, the relationship $\frac{1-\exp (-\delta)}{S_{r}^{n}-\exp (-\delta)}$ in Equation (15) can be calculated depending on particular or permissible values of $\theta_{r}$ (or $S_{r}$ ) and $d_{w t}$ (or $\delta$ ). So, it seems that in this case, the use of saturated hydraulic conductivity $K_{s}$ is necessary;

On the other side, the value of $q$ could be obtained from the analysis of water balance at the land surface as the difference between precipitation $P r$ and evapotranspiration $E T$ and water runoff; and

$>\quad$ The calculation of $L$ should be carried out taking into account the two considerations mentioned above. This means that it is necessary to estimate a particular value of $q$ with Equation (11). To achieve this, particular or permissible values of $\theta_{r}$ ( or $S_{r}$ ) and $d_{w t}$ (or $\delta$ ) can be used; however, the value of $K_{S}$ should be known in advance.

3.1.3 Case 3. Cold Humid Zones Where Subsurface Drainage Is More Intensive in Spring Time Just after Snow Melting

The main purpose of drainage in this season period is to lower down the water table and reduce soil moisture content in the arable soil layer $\left(\theta_{a r}\right)$ up to a desirable (and known) level during a limited time. Therefore, the value of $q / K_{s}$ can be calculated by means of Equation (11) considering soil moisture values of arable layer (with thickness, $z_{r}=0.2-0.3 \mathrm{~m}$ and $\left.\theta_{r}=\left(\theta_{a r}+\theta_{s}\right) / 2\right)$ instead of traditional calculation of $q$.

\subsection{Calculation Example}

The irrigated site had of loamy, non-saline, homogeneous soil with a deep impermeable layer (more than $50 \mathrm{~m}$ ). The hydrodynamic parameters of this soil are the following: $K_{s}=0.2 \mathrm{~m} /$ day, $\theta_{s}=0.50, P_{0}=0.8 \mathrm{~m}$, and $n=4.1$ for $\theta_{0}=0.12$. Note that the exponent $n$ depends on the choice of the residual moisture content $\theta_{0}$ and that $n$ decreases as $\theta_{0}$ increases. Sprinkle irrigation was used for this study. The average thickness of the root zone $z_{r}$ corresponds to $0.7 \mathrm{~m}$ and the soil moisture content $\theta_{r}$ corresponds to 0.24 . According to FAO (1980), in such conditions (relatively low permeable and non-saline soil) the $q$ value is recommended to be $0.0015 \mathrm{~m} / \mathrm{day}$. The depth of drainage pipes, $d_{d r}$, is $2 \mathrm{~m}$, the depth from drains to the impermeable layer, $d_{i l}$, is $50 \mathrm{~m}$ and the desirable depth to water table, $d_{w t}$ is considered to be $1.5 \mathrm{~m}$. The diameter of drainage pipes is $0.1 \mathrm{~m}$.

By substituting these values into the Hooghoudt's equation (Equation (2)), it results that the value of $h, D_{e}$ and $L$ corresponds to $0.5 \mathrm{~m}, 4.92 \mathrm{~m}$ and $38 \cong 40 \mathrm{~m}$, respectively.

In order to use the proposed method, we should first determine $S_{r}$ and $\delta$. Thus, $S_{r}$ is equal to $(0.24-0.12) /(0.50-$ $0.12)=0.316$ and $\delta$ is equal to $4.1(1.5-0.7 / 2) / 0.8=5.89$. After substituting these parameters into Equation (11), 
one obtain that $q / K_{s}=\left(1-\mathrm{e}^{-5.89}\right) /\left(0.316^{4.1}-\mathrm{e}^{-5.89}\right)=162$ or using directly Equation (15), it results in a drainage spacing $L$ of $45 \mathrm{~m}$.

\section{Conclusions}

Analytical methods for calculating drain spacing $L$ are based on the values of the groundwater recharge and the saturated hydraulic conductivity of the soil. However, the design of subsurface drainage should take into consideration the value of the moisture content in the root zone, as well as the unsaturated hydraulic properties of soils in the vadose zone. In this paper, it is developed an approximate analytical solution for estimating the ratio $K_{s} / q$, which can be used for calculating the drainage spacing as a function of the moisture content in the root zone, the depth to the water table, as well as other parameters such as the water retention function and the unsaturated hydraulic conductivity. The example results showed the feasibility of using a modified Hooghoudt's equation. This approach is also applicable to other equations, which contain the ratio $K_{s} / q$, such as Kirkham's and Glover equations (Ritzema, 1994). Unfortunately, the determination of the soil water retention and the unsaturated hydraulic conductivity functions is not easy and may cause some uncertainty of $q$ values. However, the described approach can be used at least to take into account the desirable water table depth and some specific characteristics of climate and soil, such as soil moisture content in the root zone and soil texture, in order to understand the dependence of groundwater recharge rate $q$ on the referred characteristics and finally to justify and select $q$ values for subsurface drainage design.

\section{Acknowledgements}

To Colegio de Postgraduados (Campus Montecillo and Campus Veracruz) for financial support. Authors also wish to thank Dr. Alejandra Ramirez-Martinez for her assistance on the revision and formatting of this article.

\section{References}

Anat, A., Duke, H., \& Corey, A. (1965). Steady upward flow from water tables (No. 7). Colorado: Colorado State University.

Averyanov, S. (1949). Hydraulic permeability of partially saturated soils. Doklady AN SSSR, 46, 200-204.

Averyanov, S. (2015). Soil water management in reclaimed agricultural lands. Russia: RTSAU Publications.

Brooks, R., \& Corey, A. (1964). Hydraulic properties of porous media and their relation to drainage design. Transactions of the ASAE, 7, 26-28. http://dx.doi.org/10.13031/2013.40684

Christen, E. W., Ayars, J. E., \& Hornbuckle, J. W. (2001). Subsurface drainage design and management in irrigated areas of Australia. Irrigation Science, 21(1), 35-43. http://dx.doi.org/ 10.1007/s002710100048

FAO. (1980). Drainage Design Factors. Irrigation and Drainage, Paper No. 38. Rome, Italy.

Fuentes, C., Zavala, M., \& Saucedo, H. (2009). Relationship between the storage coefficient and the soil-water retention curve in subsurface agricultural drainage systems: Water table drawdown. Journal of Irrigation and Drainage Engineering, 135(3), 279-285. http://dx.doi.org/10.1061/(ASCE)0733-9437(2009)135:3(279)

Fuentes-Ruiz, C., Havercamp, R., \& Parlange, J. (1991). Sobre las formas de las características hidrodinámicas de los suelos no saturados. Agrociencia, 2, 7-33. Retrieved from http://agris.fao.org/agris-search

Hay, C. (2010). Agricultural subsurface drainage systems: fundaments, benefits, impacts, and design. South Dakota University Publications [Database on the internet]. Retrieved March 16, 2016, from http://www.sdaba.org/agronomyconference/pdfs

Kladivko, E. J., Frankenberger, J. R., Jaynes, D. B., Meek, D. W., Jenkinson, B. J., \& Fausey, N. R. (2004). Nitrate leaching to subsurface drains as affected by drain spacing and changes in crop production system. Journal of Environmental Quality, 33(5), 1803-1813. http://dx.doi.org/10.2134/jeq2004.1803.

Mileham, L., Taylor, R., Thompson, J., Todd, M., \& Tindimugaya, C. (2008). Impact of rainfall distribution on the parameterisation of a soil-moisture balance model of groundwater recharge in equatorial Africa. Journal of Hydrology, 359(1), 46-58. http://dx.doi.org/10.1016/j.jhydrol.2008.06.007.

Mishra, G., \& Singh, V. (2007). A new drain spacing formula. Hydrological Sciences Journal, 52, 338-351. http://dx.doi.org/10.1623/hysj.52.2.338

Mualem, Y. (1978). Hydraulic conductivity of unsaturated porous media: generalized microscopic approach. Water Resources Research, 14, 325-334. http://dx.doi.org/10.1029/WR014i002p00325

Nikolskii, Y. (1998). Calculation of drain spacing without accounting of hydraulic conductivity and infiltration recharge. Reports of Russian Academy of Agricultural Sciences, 2, 28-31. 
Pchyolkin, V. (2003). Water regime of drained floodplains (p. 253). Moscow: Koloss Publications.

Ritzema, H. (1994). Drainage principles and applications (p. 1124). The Netherlands: ILRI Publication.

Skaggs, R., \& van Schilfgaarde, J. (1999). Agricultural drainage (p. 1328). Wisconsin: American Society of Agronomy.

Van Genuchten, M. (1980). A closed-form equation for predicting the hydraulic conductivity of unsaturated soils. Soil Science Society of America Journal, 44, 892-898. http://dx.doi.org/10.2136/sssaj1980.036159950044 00050002x

Wesseling, J. (1991). Steady state moisture flow theory; Program description; User Manual Report (Vol. 37, p. 51). Wageningen: Winand Starring Centre.

\section{Copyrights}

Copyright for this article is retained by the author(s), with first publication rights granted to the journal.

This is an open-access article distributed under the terms and conditions of the Creative Commons Attribution license (http://creativecommons.org/licenses/by/4.0/). 